\author{
Rudolf Fritsch \\ Gerda Fritsch
}

\title{
The Four-Color \\ Theorem
}

\section{History, Topological Foundations, and Idea of Proof}

\author{
Translated by Julie Peschke
}

With 42 Illustrations

Springer 
Rudolf and Gerda Fritsch

Mathematisches Institut

Ludwig-Maximilians-Universität München

Theresienstrasse 39

D-80333 München, Germany

Julie Peschke (Translator)

Department of Mathematical Sciences

University of Alberta

Edmonton, Alberta T6G2G1, Canada

The cover illustration shows a map explaining the failure in Kempe's "proof" of the Four-Color Theorem. See page 176.

\section{Mathematics Subject Classification (2000) 01A05}

Library of Congress Cataloging-in-Publication Data

Fritsch, Rudolf, 1939-

[Vierfarbensatz. English.]

The four color theorem / Rudolf Fritsch, Gerda Fritsch.

p. $\mathrm{cm}$.

Includes bibliographical references (p. - ) and index.

ISBN 978-1-4612-7254-0 ISBN 978-1-4612-1720-6 (eBook)

DOI 10.1007/978-1-4612-1720-6

1. Four-color problem. I. Fritsch, Gerda. II. Title.

QA618.12.F7513 1998

$511.5-\mathrm{dc} 21$

98-11967

Printed on acid-free paper.

Original title: Der Vierfarbensatz, by Rudolf and Gerda Fritsch

- 1994 Bibliographisches Institut \& F.A. Brockhaus

- 1998 Springer Science+Business Media New York

Originally published by Springer-Verlag New York, Inc. in 1998

All rights reserved. This work may not be translated or copied in whole or in part without the written permission of the publisher Springer Science+Business Media, LLC.

except for brief excerpts in connection with reviews or scholarly

analysis. Use in connection with any form of information storage and retrieval, electronic adaptation, computer software, or by similar or dissimilar methodology now known or hereafter developed is forbidden.

The use of general descriptive names, trade names, trademarks, etc., in this publication, even if the former are not especially identified, is not to be taken as a sign that such names, as understood by the Trade Marks and Merchandise Marks Act, may accordingly be used freely by anyone.

Production managed by Lesley Poliner; manufacturing supervised by Thomas King. Photocomposed copy prepared from the translator's $\mathrm{LT}_{\mathrm{E}} \mathrm{X}$ file. 


\section{The Four-Color Theorem}


Springer Science+Business Media, LLC 
To

Dorothee, Veronica, and Bernhard 


\section{Preface}

During the university reform of the 1970s, the classical Faculty of Science of the venerable Ludwig-Maximilians-Universität in Munich was divided into five smaller faculties. One was for mathematics, the others for physics, chemistry and pharmaceutics, biology, and the earth sciences. Nevertheless, in order to maintain an exchange of ideas between the various disciplines and so as not to permit the complete undermining of the original notion of "universitas," Carl-Friedrich-von-Siemens Foundation periodically invites the professors from the former Faculty of Science to a luncheon gathering. These are working luncheons during which recent developments in the various disciplines are presented by means of short talks. The motivation for such talks does not come, in the majority of cases, from the respective subject itself, but from another discipline that is loosely affiliated with it.

In this way, the controversy over the modern methods used in the proof of the Four-Color Theorem had also spread to disciplines outside of mathematics. I, as a trained algebraic topologist, was asked to comment on this. Naturally, I was acquainted with the Four-Color

${ }^{1}$ A Latin word meaning the whole of something, a collective entirety. 
Problem but, up to that point, had never intensively studied it. As an outsider, ${ }^{2}$ I dove into the material, not so much to achieve any scientific progress with it but to make this already achieved objective more understandable.

My talk on this subject was given in the winter semester of $1987 / 88$, and it generated interest among my colleagues. This brought to mind my primary jurisdiction-the Professorship for Mathematical Education at the University of Munich. I then began to think about how one could make the mathematical workings of the Four-Color Problem more accessible to student and professor alike-many of whom were already fascinated by this famous problem.

This led to a lecture at the 80th gathering of the Deutscher Verein zur Förderung des mathematischen und naturwissenschaftlichen Unterrichts (German Association for the Advancement of Teaching in Mathematics and the Sciences), which was held in 1989 in Darmstadt [FRITSCH 1990]. The director of B.I. Wissenschaftsverlag, who attended that meeting, approached me about formulating more precisely my thoughts on this matter-from the point of view of an outsider to other interested outsiders. In other words, I was to put them into book form.

Therefore, this book has been written to explain the Four-Color Theorem to a lay readership. It is for this reason that a chapter on the historical development and the people involved in it has also been included. When my efforts concerning the historical side of things bogged down, I managed to persuade my wife to take on this task. She dedicated herself to it wholeheartedly, for which I am truly grateful.

From the point of view of mathematical research, much has already been written about the Four-Color Theorem-before, during, and after the completion of its proof. There exist a number of firstrate complete presentations of which the interested and professional mathematician can avail him/herself. I will mention just a few of them: for the time "prior," the book of Oysten Ore [ORE 1967]; for the

${ }^{2}$ I regard as "insiders" those mathematicians who have devoted themselves to graph theory and combinatorics. 
period "during," the book of Thomas Saaty and Paul Kainen [SAATY and KAINEN 1977]; and for "after" the fact, the book of Martin Aigner [AIGNER 1984].

In the task set before me, the following problem arose. The intuitive presentation of maps is topological in nature. The everwidening rings around the proof of the Four-Color Theorem, however, are fraught with purely combinatorial difficulties. The topological side in most of the presentations is somewhat neglected. Perhaps this is because it is viewed as being trivial or uninteresting. Many of the required theorems are so intuitively clear that one considers them not needing any proof at all. Here is an example:

In the plane, let $B$ be an arc. Let $\mathbf{x}$ be an end point of $B$. Then every point not lying in $B$ can be joined to $\mathbf{x}$ by an arc that intersects $B$ only at the point $\mathbf{x}$.

However, a proof of this claim cannot be found in the truly comprehensive textbook Lehrbuch der Topologie [RINow 1975]. On page 409, the author writes: As we, in the future, will not be needing this particular theorem on arcwise accessibility, we will omit the somewhat long and drawn-out proof. Nowadays, the much-discussed subject of fractal geometry has, however, sharpened the eye precisely for such problematic issues. ${ }^{3}$ From this, it has become apparent that the transition from topology to combinatorics is possible to present-even in the desired way. It just requires deep results of modern topology. These, however, cannot be fully presented within the limited pages of this little book, meaning that all of the proofs cannot be included as well. Nonetheless, the facts are presented, and references for the more extensive proofs are supplied. The most valuable source of information is Dugundji's book Topology [Dugundu 1966]. Even this book does not contain everything that is necessary. One must still draw upon particular techniques that come from piecewise linear and geometric topology. Most of these can be found in Moise's Geometric Topology in Dimensions 2 and 3 [MOISE 1977].

\footnotetext{
${ }^{3}$ It has even been suggested to include the notion of "monster curves" in the school curriculum. Monster curves are an interesting topic for this book because they highlight the difficulties inherent in the mathematical definition of maps [NEIDHARDT 1990].
} 
The third part of this book treats the combinatorial methods that constitute the actual content of the Four-Color Theorem. This need not be discussed here in any further detail.

Many colleagues and friends must be thanked for their efforts in supplying both historical and mathematical information to us. They were plied with many questions in conversations and in correspondence. In 1990, at the fiftieth anniversary of the Deutsche Mathematiker-Vereinigung (German Mathematical Association) in Bremen, Wolfgang Haken gave a full account of this problem. Jean Mayer sent very helpful letters. By means of "electronic mail," Karl Dürre, Kenneth Appel, and John Koch were exceedingly friendly and patient in answering a continuous stream of inquiries. We are not able to mention here all who have helped us. They simply must excuse the omission.

A final thank you goes to Mrs. Bartels and Mr. Engesser of B.I. Wissenschaftsverlag who have obligingly granted special requests for the provision of facsimiles and illustrations and who have gone to great lengths to procure them-sometimes a very difficult task. A friend and colleague of mine who did a great deal in the way of proofreading has requested to remain anonymous.

Rudolf Fritsch

München, Germany

October 23, 1993 


\section{Acknowledgments for the English Edition}

Our express thanks to Julie Peschke, who not only excellently performed the difficult task of translation but also, as a mathematician, discovered many (hopefully almost all) misprints, inaccuracies, and even errors in the German edition.

Special thanks also go to Tom von Foerster, of Springer-Verlag, New York who accepted the book for publication in this renowned publishing company and accompanied the preparation of this edition with many very helpful suggestions. The detailed work of the production of this book was in the hands of Lesley Poliner, Anne Fossella and David Kramer to all of whom we are very much obliged, in particular to Lesley Poliner for her competent and kind cooperation and patience with the authors.

Rudolf Fritsch and Gerda Fritsch München, Germany May 11, 1998 


\section{Ways to Read This Book}

First and foremost everyone should read this book out of personal interest! Chapter 1 contains the historical development in so far as can be presented without a wide range of conceptual explanations of a mathematical nature. In addition, it presents particular biographical information about the lead players in this mathematical drama. The succeeding chapters, too, touch time and again on the historical backdrop but are more oriented towards the germinating ideas and their formulations and less to the personalities themselves. Chapter 2 deals with the topological foundations. The ideas in this chapter are particularly important for those who ultimately seek a deeper understanding of the material. One should attempt, at least, to master the statements of the theorems and their meanings. The proofs of the theorems and the often highly technical lemmas one can, on the first reading, gloss over or simply omit.

Those who want very quickly to get to the heart of the Four-Color Theorem and the technical difficulties associated with it can begin reading at Chapter 3 . There one finds a precise formulation of the topological version of the theorem and a few of its related problems. As to understanding the proofs, it suffices to look up the relevant concepts that have been defined previously in Chapter 2 . 
A reader who, on the other hand, is familiar with the Euler characteristic and has a basic understanding of graph theory may begin reading this book with Section 6 of Chapter 4 . This section contains the entire foundational material and all of the important mathematical formulae required for the proof of the Four-Color Theorem. Sections 4.7 and 4.8 can be skipped. A thorough reading of Chapters 5,6 , and 7 is advisable for whoever wants to gain an impression (and an appreciation) of the technicalities of the proof of the theorem itself. 


\section{Contents}

Preface vii

Acknowledgments for the English Edition xi

Ways to Read This Book xiii

1 History 1

2 (Topological) Maps 43

2.1 Preliminary Considerations . . . . . . . . . . . . 43

2.2 Borderlines . . . . . . . . . . . . . . 46

2.3 The Formal Definition of Maps . . . . . . . . . . . 59

2.4 Basic Examples . . . . . . . . . . . . . . . . . . . 68

2.5 National Borders . . . . . . . . . . . . . . . . 73

2.6 Common Borderlines . . . . . . . . . . . . . 77

2.7 The Extension of Maps . . . . . . . . . . . . 81

3 The Four-Color Theorem (Topological Version) 85

3.1 Formulation and Basic Approach . . . . . . . . . . 85

3.2 First Steps Towards the Proof . . . . . . . . . . . 87 
4 Topology to Combinatorics 99

4.1 Complete (Plane) Graphs . . . . . . . . . . . . . . . . 99

4.2 The Wagner and Fáry Theorem . . . . . . . . . . 105

4.3 The Euler Polyhedral Formula . . . . . . . . . . . . . 114

4.4 Duality . . . . . . . . . . . . . . . . . 118

4.5 Cubic Maps . . . . . . . . . . . . . . . . 125

4.6 Counting Arguments . . . . . . . . . . . . . . . . . 129

4.7 The Five-Color Theorem . . . . . . . . . . . . . 133

4.8 Tait's Reformulation . . . . . . . . . . . . . . 134

5 The Four-Color Theorem (Combinatorial Version) 139

5.1 Vertex Colorings . . . . . . . . . . . . . . . . 139

5.2 Planar Graphs . . . . . . . . . . . . . . . . . . . . . 141

5.3 Formulation and Further Advances . . . . . . . . . 149

5.4 Rings and Configurations . . . . . . . . . . . . . . 152

5.5 And Now, to the Proof! . . . . . . . . . . . . . 168

6 Reducibility 171

6.1 Kempe Chain Games . . . . . . . . . . . . . . . . . . 171

6.2 The Birkhoff Number and Some History . . . . . . 184

6.3 Types of Reducibility . . . . . . . . . . . . . . 186

6.4 The Dürre-Heesch Algorithm . . . . . . . . . . . 187

$6.5 A-, B$-, and $C$-Reducibility . . . . . . . . . . 208

7 The Quest for Unavoidable Sets 219

7.1 Obstructions and a "Rule of Thumb" . . . . . . . . 219

7.2 Discharging Procedures . . . . . . . . . . . . 223

$\begin{array}{ll}\text { Bibliography } & 231\end{array}$

$\begin{array}{ll}\text { Works of Reference } & 249\end{array}$

Index 